\title{
EL DESTELLO DE LA GRATUIDAD: LA III GUERRA MUNDIAL DE ANDI NACHON
}

\author{
Por Nadia Prado
}

\begin{abstract}
Un pensamiento nunca comienza espontáneamente, por si solo, con sus principios inherentes -lo que nos incita a pensar siempre es un encuentro traumático con algún Real externo que se impone a nosotros brutalmente, destruyendo nuestras formas establecidas de pensar-. Como tal, un verdadero pensamiento siempre es descentrado: no pensamos espontáneamente, somos forzados a pensar ${ }^{1}$.
\end{abstract}

Slavoj Žižek

\footnotetext{
${ }^{1}$ Este pasaje de Žižek mantiene un diálogo con Deleuze, rescatando el modo en que el pensador francés atiende al impacto de lo real en el pensamiento. Véase Slavoj Žižek, "Da Capo senza Fine", en Judith Butler, Ernesto Laclau, Slavoj Zižek, Contingencia, hegemonía, universalidad. Diálogos contemporáneos en la izquierda, Buenos Aires, Fondo de Cultura Económica, 2004, pág. 215.
}

$N^{\circ}$ 2. Segundo Semestre de 2014 
Resumen: Este trabajo es una lectura del poemario La III Guerra Mundial de Andi Nachon, donde se reflexiona sobre una escritura que lee la dictadura argentina y escribe sus marcas mostrando la construcción de una subjetividad descentrada, que entiende el poema como destello de una potencia y posibilidad de la alteridad en medio de la catástrofe. Vértigo de la existencia que acontece como memoria fisurada de la infancia y de la animalidad política en que esa infancia debe habitar, siendo la experiencia poética posible gracias a la vivencia del viaje como huida, cuya conmoción, lateral o directa, ingresa en el simulacro para soportar la verdadera existencia y la violencia. País, sur, madre, hermano, hija han sido estallados antes de comenzar el viaje y ese estallido es lo que perdurará.

Palabras clave: Poesía-memoria-viajedictadura-violencia.

\begin{abstract}
The following paper is a reading of La III Guerra Mundial by Andy Nachon, a book of poems that reflects upon the Argentinian Dictatorship and writes about its marks, by portraying the construction of an offcenter subjectivity that understands the poem as a glint of power and a possibility for otherness in the middle of disaster. Vertigo of an existence that appears as the fissured memory of childhood and the political animality that childhood must inhabit, the poetic experience seems possible due to the experience of journey as an escape; whose awe, whether lateral or direct, joins the simulacrum to bear true existence and violence. Country, south, mother, brother and daughter have been before starting the journey, which is the only thing that will last.
\end{abstract}

Keywords: Poetry-memory-journeydictatorship-violence. 


\section{Exordio}

Andi Nachon ${ }^{2}$ nació en agosto de 1970, seis años antes de que María Estela Martínez de Perón, conocida como Isabel Perón, fuera detenida tras el golpe de Estado que inaugura la sangrienta dictadura cívico-militar argentina que se prolongó por siete años. En Chile, el horror se había adelantado treinta y seis meses con el derrocamiento del presidente Salvador Allende y se extendería hasta 1990, sin embargo estábamos en lo mismo: abolidos y revocados ante el fascismo cívico-militarempresarial triunfante.

Nachon, veinte años más tarde, forma parte de esa tribu de poetas de la década de los noventa, a quien Arturo Carrera alguna vez llamó monstruos, en el sentido etimológico de la palabra: "mostrar espectacularmente", con lo que quería aludir a su espectáculo de, como él mismo señala, "mostrar el contraste de juventudes, [pero sobre todo] de poéticas" (2001, p. 11). Eran las voces que emergían a fines de los años ochenta y principio de los noventa y que, luego, arribarían al siglo XXI esperando nuevas catástrofes. Esa tribu a la que se refiere Carrera fue antologada posteriormente por Nachon ${ }^{3}$.

2 Ha publicado los libros de poesía Siam (Buenos Aires: Nusud, 1990); W.A.R.Z.S.A.W.A. (Buenos Aires: Bajo la Luna Nueva, 1996); Taiga (Buenos Aires: Suscripción, 2000); De vos a mí (Buenos Aires, 2002); Goa (Buenos Aires: Tsé Tsé, 2003); Villa Ballesta/Nuñork (Santiago: Surada, 2003); Plaza Real (Buenos Aires: La Bohemia, 2004); 36 movimientos hasta (Buenos Aires: La Bohemia, 2005); Volumen I (Buenos Aires: Peek-a-boo, 2010); Suave por la corriente (Buenos Aires: Peek-a-boo, s/a); y La III Guerra Mundial (Buenos Aires: Bajo la Luna, 2013). También compiló la antología Poetas argentinas 1961-1980 (Buenos Aires: Ediciones del Dock, 2007).

3 Es muy importante esta "tribu" de poetas de los años noventa que intenta registrar un cambio de aliento, aun cuando tiene a la vista siempre la enorme tradición argentina de poetas que los anteceden como Joaquín Giannuzzi, Juan Gelman, Leonidas Lamborghini, Juan L. Ortiz, Alejandra Pizarnik y Olga Orozco, o la generación $N^{\circ}$ 2. Segundo Semestre de 2014 
Seleccionó a más de cincuenta poetas que provienen de una larga y excelente tradición argentina de escritoras a quien su disparidad, cercanía, pero también distancia, como ocurre en Chile, le da su fuerza. Se trata, como dice Delfina Muschietti, de:

"Los chicos de los noventa [que] tienen propuestas particulares; y aunque su poesía es sumamente heterogénea, se puede escuchar un tono que los une: (...) cierto desprejuicio para con la poesía, una forma de acercamiento al lenguaje poético muy diferente de la que se tenía veinte años atrás, y que se liga con la fuerte relación entre cultura alta y cultura de masas (...) [es] una relación muy diferente a la que se tenía en los años setenta. Entonces se podía trabajar con la cultura de masas, pero con una distancia operacional, con un esfuerzo por incorporarla. En cambio, en el poema de un joven de los años noventa, puede aparecer "naturalmente" una cita de Joyce junto a la figura de Betty Boop." (Carrera, 2001, p. 15-16)

Así se estaba, despojados de experiencia para algunos y llenos de la posibilidad de alcanzarla para otros. Como fuera, inmersos en la sociedad mediática, se escribía intentando escapar de la ley social desactivante y de consumo y oscilando entre la insignificancia y la suficiencia; en la opresión o en la libertad de lo cotidiano, dependiendo de cuán capaces éramos de habitar la vida para que la "experiencia [condensara] como

inmediatamente posterior donde encontramos a Néstor Perlongher, Osvaldo Lamborghini y Diana Bellessi, entre otros, "porque marcan una (...) reterritorialización de los espacios que produce un enorme movimiento [...] porque se ha echado a andar un proceso de simbolización donde se reconfigura el lenguaje poético. Hay una nueva territorialidad en los textos, se ponen en escena otros referentes que dejan explicitado el deseo de que las impurezas irrumpan en el terreno de la lírica" (Genovese, 2003, p. 200). 
una perla" (Agamben, 2001, p. 9). Allí, la vida poética -que como toda experiencia- "no tiene su correlato necesario en el conocimiento, sino en la (...) palabra y el relato" (Agamben, 2001, 9), siempre nos insufla algo más, aun cuando arrecie el nihilismo y la indiferencia. En esa y esta época, en el habla entre dos siglos, Andi Nachon escribe procurando que la experiencia poética no sea capturada y se consagre como "esa región donde todo es posible" (Nachon, 2013) ${ }^{4}$, en que el yo es movible, varía, se reinventa y refugia en su "galaxia propia" (Nachon, 2013) sin darle la espalda al mundo.

La III Guerra Mundial de Nachon lee la dictadura argentina y escribe sus marcas con posterioridad, exhibiendo la construcción de una subjetividad descentrada que, sin embargo, el poema centra, entendiéndolo como destello de una potencia y posibilidad de la alteridad en medio de la catástrofe. Lo que nos muestra esta poética es un palabra que dice en medio de la obligatoriedad de vivir, porque lo que dice el poema es, precisamente, ese vértigo de la existencia cuando la catástrofe se despliega. Vértigo que acontece en esta escritura como memoria fisurada de la infancia ante la animalidad política en la que esa infancia debe habitar, siendo la experiencia poética posible gracias a la vivencia del viaje como huida o, más específicamente, intento de huida, cuya conmoción, lateral o directa, ingresa en un simulacro para soportar la verdadera existencia.

El viaje, en tanto refugio, no evita esa manera lateral con que a veces la violencia nos toca, y nos toca a la manera de un retiro o un simulacro para poder, quizás, vivir, por un no

\footnotetext{
${ }^{4}$ Entrevista a la poeta por Aníbal Cristobo, “Andi Nachon: Micropolíticas de la resistencia”, domingo 14 de agosto de 2011 [en línea], http://kriller71.blogspot.com/2011/08/entrevista-andi-nachon-micropoliticas.html. $N^{\circ}$ 2. Segundo Semestre de 2014
} 
querer saber lo que era imposible no saber. País, sur, madre, hermano, hija han sido estallados antes de comenzar el viaje y ese estallido es lo que perdurará.

Vemos tres formas de ese horizonte estallado en La III Guerra Mundial: la primera se sostiene en el estatuto del juego: jugar a la III Guerra Mundial, que se ensaya en el viaje-huida en las figuras de la niña y su hermano ${ }^{5}$; la segunda refiere a cómo la identidad de género se presenta en la relación entre la niña pequeña y su hermano mayor, descrito como el héroe, a quien admira y quien la desafía constantemente; y la última forma, y la que más nos interesa, tiene que ver con la memoria y cómo esta se despliega en una memoria interior, una memoria exterior y una mezcla de ambas.

\footnotetext{
${ }^{5}$ Que aparece como Rolando en la dedicatoria y que es el Sargento Sanders a quien está dedicado W.A.R.Z.S.A.W.A., el segundo libro de poesía de Nachon.
} 


\section{Algo más}

Importa decir que esta caminata por el libro de Nachon no intentará ir descifrando, interpretando o planteando hipótesis rigurosas -a eso me resisto-, sino más bien leerescribiendo y reflexionar ese entre de un pensamiento poético que, desde siempre, ha celebrado la gratuidad y la piedad por los detalles. Se trata de una lectura -siempre liminar y posiblemente reduccionista- que se deja llevar por el camino, pensando y escribiendo con el libro. Por este poema solo puedo caminar, caminar es no apropiarme de él, más bien quisiera ser ese sujeto que dice somos "fragmentos, mezcla de poemas, poemas que otros escribieron” (Marchant, 2009, p. 353). Es decir, pensar con palabras y bacia-primeramente y quizás solo eso. La erosión de una hoja escribe sobre la otra y las hojas se deshacen y vuelan, aflorando "la vida latente y el temible poder de ese elemento aún adormecido" (Henri Bosco, ctd. en Bachelard, 2000, p. 54). Hacia el otro lado extender mi mano, cruzando la cordillera, una montaña, elevación accidentada y siempre aconteciente. Porque el poema "se sitúa precisamente a ese nivel pre-sintáctico y pre-lógico, (...) pero también predevelador: en el momento del puro tacto, del puro contacto, del sobrecogimiento, de la opresión que es, tal vez, una manera de dar hasta la mano que da. Lenguaje de la proximidad por la proximidad (...) responsabilidad por el prójimo que gracias a su para el otro hace posible toda la maravilla del dar" (Levinas, 1995, p. 176).

Aclarar, entonces, que no es mi interés fijar o resolver los procedimientos lingüísticos que esta escritura utiliza, sino leer con ella y escribir mientras leo, porque creo que el poema -en 
su arrojo hacia el otro y con él hacia el lenguaje del otro- nos hace existir entrelazados a través de las palabras. Solo así podemos poetizar, correspondernos y seguir leyendo. Es un diálogo que ha creado su hogar y al que volvemos cada cierto tiempo: reciprocidad del vértigo. 


\section{Primer horizonte: restituirse en el juego}

La poesía, como sabemos, no solo interpreta el mundo sino que lo transforma, y más aún, trastorna la verdad que se preguntará -luego de esta dislocación, desde siempre y ahoradudando, visitando la realidad particular y respetando al otro en su pluralidad y en su diferencia, única manera posible para mantenerse alejado de lo obsceno y de lo grotesco, es decir, mantenerse medianamente a flote. Por lo tanto, transito esta lectura, como si la hoja fuera por un delta, cuya posibilidad de irrupción y señales me fueran adentrando en el pensamiento y en la poesía, que suspende, no para sustraer la catástrofe, sino porque "[e]l poeta y el que piensa son, como el Demiurgo, un pais paizon, un niño que juega" (Cacciari, 2000, p. 23). Cada camino, en su particularidad, en tanto seña, gesto, respiración, aliento, abre un espacio, cuyo tono es apenas rodeo, sesgo y deseo. Allí, una forma de leer, allí una forma de decir, modulación y variabilidad de la lectura y de la escritura. El poema le hace algo al pensamiento, el poema tantea esa imagen en su vibración.

$\mathrm{Ni}$ el juego ni el viaje abren la clausura, pero suspenden el tiempo inevitable y asfixiante bajo amenaza. Huida como simulacro, como recreo y suspensión del horror. Escribe Nachon: "Cielo y más cielo / para los días sin fin: dieciocho" (2013, 16). Qué es esta poética, esta III Guerra Mundial de Andi, qué es esta particularidad irradiada de lo inconmensurable: redundancia del pensamiento, instante, azar. Ningún yo vivo, pleno, sino dislocado, un yo agonizante y despedazado ante los acontecimientos que en su horror nos enmudecen cuando el miedo se aloja en las piernas, porque son: " $[\mathrm{H}]$ oras 
de luz en destello / [que] corren tras la ventanilla del auto / en avance constante. Cielo / y más cielo es esto que / indiferentes navegamos" (Nachon, 2013, p. 16).

Entonces, el camino hacia las palabras se intenta, solo eso, y algo se vuelve impreciso, como si las palabras liberaran el olvido que las habita desde siempre, incluso en el eco que retorna espectral a decirnos, a pesar de esa indiferencia por la que se navega, debes seguir viviendo, a pesar de todo. A pesar de "[q]ue explote el planeta, no haya agua / tiempo / no haya más. Calma. Que de una vez / estalle todo lo conocido / que no nos corresponde / hermanito, sí, seamos fugitivos y hagamos / al menos algo en la huida" (Nachon, 2013, p. 47).

Se intenta vivir en medio del estallido, jugando, es decir, descubriendo como forma de relación constituyente de todos los sujetos, alterando el repertorio, pasando las horas, y cuyas pérdidas son posibles de subsanar en un nuevo juego. La calma se extingue, el agua, el tiempo, todo estalla, por eso el juego reúne y es, también, la posibilidad de la fuga y de la huida, porque "en medio del recreo continuo y las múltiples diversiones, las horas, los días, las semanas pasa[n] como relámpagos [y] la aceleración del tiempo no deja de modificar el calendario" (Agamben, 2001, p. 96). La autora desea "[q]ue de una vez / estalle todo lo conocido" (2013, p. 47), porque comprende y lo dice "no nos corresponde, hermano mío/ casi dos metros, quince años mayor/ y sos un niño" (p. 47), aun cuando "El hermano mayor ama la valentía: kamikazes/ soldados prusianos o guerrillas" (54). Sin embargo, se desea "[1]a supervivencia [que] impone con orden impecable su definitiva claridad" (p. 54). La memoria se entrelaza con los 
años de juego irremontables e inolvidables cuando el juego solo queda como recuerdo, porque "[e]n la distancia / sin darnos cuenta el tiempo pasará y a sus casi / sesenta años, eso seguirá igual" (p. 54). Nada queda del pasado o todo se desdibuja y el estatuto de la complicidad se trastoca. Escribe Nachon: "Tu hermano mayor / será esta sombra que convocarás / si atacan zombis y los cielos / al fin estallan. En vos, sin darte cuenta / también esto pasará: esa hermanita que confió / en la validez de una guerra / sólo por confiar en él" (p. 54).

Es un yo que, aun cuando intenta volver sobre sus pasos a través de la escritura, sabe lo insuperable de un tiempo que no reincide de la misma manera. Ese tiempo en que se imaginaba, a través del juego, para dejar al lado la catástrofe. Entonces, ahora, se escribe, se participa de otras voces y en el intervalo habita la que alguna vez tuvimos, mientras en el viaje se avizoran los papeles a jugar cuando la niña dice: "Soy buena copiloto, aunque no lea mapas y pasen / los carteles a la velocidad de la luz / nunca me duermo ni dejo solo / al conductor con su magia / en avanzada constante" (p. 12).

¿Cómo volver entonces a ese tiempo sin tiempo, a esa marca inaugural, dispersión de los restos, dispersión de las voces? No hay respuesta, sino un mientras en que se trata de continuar en este otro tiempo donde, aun cuando hay reglas, todas las jerarquías se suspenden y la memoria puede introducir el olvido. Nunca dormir es nunca me olvido, nunca me olvido sobre todo de mí; esfinge que observa en vigilia constante sin manejar la carta de navegación, solo confiada en el 
avance y por quien es conducida. Impersonal pero alerta, con los sentidos en el camino.

La III Guerra Mundial de Andi Nachon es el viaje de un camino iniciático impulsado por el miedo en el que el sur, como lugar de destino, opera como refugio y posibilidad para empezar de nuevo. Se trata de un viaje enmascarado -simulacro de vacaciones- donde el deseo por ese espacio inmenso guía la urgencia por salir de la ciudad devastada por la violencia. Esto permite la amplificación de la memoria de sus protagonistas, especialmente la de los niños, que viven su propia guerra como juego, pero como posibilidad de un trayecto en el que se indaga la vida: "Tu hermano mayor y vos / al sur la travesía, una búsqueda de otra vida / que empieza en un final" (p. 11).

¿Qué podría ser una vida que comienza en un final? Se trata acaso de un desenlace o de la consumación en la fuga, por cuanto la dictadura hace acontecer el sur como promesa y mundo imaginario que ocurre de manera sesgada a la realidad sufrida por el país, en que el tiempo se trastoca y la realidad se espesa y se configura desde el desplazamiento: "Soy / buena copiloto y ya: desde los cuatro lo sé y cada / viaje o este único / largo viaje interminable / con su movimiento marcan / su propia realidad" (p. 12).

Es la vivencia del horror desde la mirada de una niña que ficciona, mientras se aferra a su héroe que, en su estatuto magnánimo, puede hacer que otros sobrevivan. Sin embargo, el terror de la huida crece, paradójicamente, en lo ilimitado que se transita en la asfixia del pequeño espacio del auto. Andi escribe: "Cuando fui chica la familia / nucleaba en su Chevy 
naranja / el terror de la huida" (p. 12). Hay en este desplazamiento $-\mathrm{y}$ en este juego que simula una guerra mundial dentro de una guerra nacional-, derivaciones, destellos, suspensiones, olvidos, desvíos y complicidades: maneras de hacerle frente a la catástrofe y darle sentido a la vida. El epígrafe de Orson Scott Card que abre el libro ya nos da noticia de este amor en medio del dolor: "Como solo se puede amar a alguien que es un eco de uno mismo, en el momento de la pena más profunda".

Esto que ha comenzado en algún dolor es el viaje, el juego, la huida en el Cheavy, un abrirse camino para seguir "adelante y a salvo" (p. 13) y, a pesar de todo, en medio del peligro. Muestra de ello es cuando la reflexión alcanza su lucidez más alta: "[C]omo toda copiloto sé / no hay viaje sin fuga y nada hay / que no haya / empezado en algún dolor" ( $p$. 12). Así, el poema es memoria de una realidad que el inconsciente ha debido desfigurar, pero que ha hecho consciente en la escritura. El poeta intenta evitar el desmayo, la disolución de la subjetividad para recuperarse del horror que tiene ante sí, del mundo que se ha vuelto siniestro. Se crece entre "Mapas, rutas, accesos cortados / (...) navegando" y con la "fe en la catástrofe" (p. 11). Fe que designa la posibilidad del desvío donde "cada vacación [es] un simulacro: Caracoles, Camarones / Los Toldos. Esta cartografía final / desplegada en la mesa familiar / donde hombro contra hombro / rastreamos huidas posibles (p. 11).

El simulacro, que pone en duda y suplanta el mundo devastado, acoge la enajenación del sujeto, sin embargo, aloja un profundo drama: no se puede pretender olvidar lo real 
aunque haya sido maqueteado de antemano. Entonces, ¿qué huida?, ¿hacia dónde?, "¿qué puede significar una salida ahí mismo donde no hay ningún afuera, ningún otro lugar?" (Malabou 2010, p. 8), porque "no se trata de escapar de la clausura sino de cómo escapar en la clausura misma" (Malabou, 2010, p. 8).

La huida, solo como posibilidad, nos enfrenta a aquello que en el camino nos detendrá, nos cortará el paso y "súbitamente todo explotará" (Nachon, 2013, p. 11). Mientras, en el trayecto, se ensayan conversaciones y tácticas para la guerra imaginaria que está aconteciendo y que los acompaña: "para vos la tercera guerra / se traslada por esa fuga / donde él y vos hallarán cobijo / entre un pueblo sin nombre y otro" (Nachon, 2013, p. 11). Estos juegos, este viaje -como cobijo-, entrelazan el miedo y el espesor que es dispositivo para la escritura que logra acoger una subjetividad colapsada. Es la forma en que el terror atraviesa a estos sujetos, de forma fronteriza y directa a la vez. La catástrofe del país ya no está simplemente afuera o en otro lugar, sino en los sujetos mismos y en toda salida que emprendan; es constitutiva de toda acción para escapar de los márgenes de la violencia, porque todo es orillado por el desastre. Los que viajan en este libro son parte de esta tragedia que intentan no vivir; la madre por producir la huida y los niños ensimismados por el viaje y por el juego. Pero la niña recobra poéticamente, y años después, su lucidez: "Cielos enormes sin más fin / que sus mismas tardes, rutas / recorridas sobre el vértigo / como rastreo / sin sitio a alcanzar. De la perdición / tu hermano mayor anhela su orden: blanco / la mira / exhalación. Zona de nadie donde toda / guerra 
instala / una guerra entre hermanos" (Nachon, 2013, p. 27).

El hogar, el cielo, se han desplazado, la madre es presa del pánico y los niños se introducen ficticiamente en un juego, en una guerra en que son protagonistas y que, sin saberlo, reproduce la violencia del país y la guerra entre sus ciudadanos, y allí, "rutas recorridas sobre el vértigo" (Nachon, 2013, 27). La violencia incesante de la dictadura argentina que torturó, asesinó y dejo más de treinta mil desaparecidos es parte de ese viaje. El viaje se vuelve, como juego, el territorio de la violencia, en tanto itinerario de disputa, porque el juego que se lleva a cabo no es cualquiera: se recrea una guerra, es decir, los sujetos, los niños producen la guerra, eligen la guerra como acumulación y derivación de la violencia del país. Esta sería, por lo tanto, la violencia vicaria que recae en la infancia, en tanto acontece, con los sujetos, la violencia del país que parece consumarse en el juego inocente de los niños. El viaje, para la madre, es el intento de salida desde un mundo amenazante hacia el sur en "búsqueda de otra vida" (Nachon, 2013, p. 11); y el juego, para los niños, es la posibilidad de reunión y "frentes de guerra para el héroe" (17), "simulacros de control" (2013, p. 21) y "cada vacación una puesta en escena de la huida" (2013, p. 33), pero la fuga traslada todo. La locura familiar es la locura del país y la locura de la lengua donde esta se vuelve pura "exhalación" y "zona de nadie" cuando acoge el juego de la guerra. 


\section{Segundo horizonte: complementos filiales}

Las situaciones y objetos en medio de esas acciones se superponen, juego y juguetes hacen el "pequeño reino de los niños” (Agamben, 2001, p. 95) o quizás “esa utópica república infantil (...) la imagen de un universo donde todo es juego" (Agamben, 2001, p. 95), abriendo otro espacio-tiempo donde estos se modifican y aceleran. En este tiempo vive y convive esta niña, que cree y observa cómo el héroe (su hermano) inventa en el viaje un modo de relación con ella y con el mundo. Divisa o emblema distintivo entre ambos para diferenciarse. Pero de qué nos estamos diferenciando siempre, respecto de qué marcamos esta distancia, en especial cuando no hay oportunidad ni territorio donde ejercer ese combate porque todo ha sido destruido y cooptado.

Ese héroe se despliega para los ojos de la niña, en medio de ese afuera absurdo, derrumbado y paranoico que ratifica la locura de este juego, de esta guerra no imaginaria, pero que aún no ha llegado. ¿Qué pasaría si llegara?, ¿la mujer sería, como en toda guerra, el botín de intercambio sexual y económico? Y luego, qué ha sido mutilado en ese niño que necesita poner en práctica un sinnúmero de habilidades o rasgos idealizados en ese ejercicio heroico y, por lo tanto, debe dejar de ser algo para llegar a ser otra cosa que él y para ser reconocido como tal por su hermana.

Luego quien observa al héroe le debe un tributo, y el héroe se hace hombre para la niña. Escribe Andi dando cuenta del acopio de objetos simuladores para lo bélico: "Alguna vez / tu hermano mayor dejó atrás al debilucho / y arrastró a la madre de compras: su primer trofeo / culata blanca el revólver, 
delicado y casi / para la cartera de una dama" (Nachon, 2013, 14).

El vínculo reconstruye el lugar de la subalternidad de la mujer, en la medida en que el amor entre la niña y su hermano y de este con la madre acontece como realización que no quebranta la ley social y la tradicional construcción del sujeto femenino como efecto de relaciones psicosociales, económicas y de dominio. Se trata de una complicidad y una admiración basada en el contrato social heterosexual que, según Wittig, hay que destruir, pues coarta la posibilidad de reciprocidad y, por ende, de libertad para las mujeres ${ }^{6}$. "Del hermano mayor, la colección ahora / abarca toda la superficie de su cama: un / fusil de asalto, la colt cromada o el winchester / que en perfección merece / su lugar de exhibición (Nachon, 2013, 14).

La madre existe factualmente y en las mercancías de valor que son los juguetes en este reino, mientras que el padre solo acontece para desviar su propia falta: "Los días del padre / vos mentirás en la escuela regalos / rutinas de paseo a sabiendas que / las verdades familiares no se enuncian / de ninguna manera" (Nachon, 2013, 15). La identidad de género se presenta en la relación entre la niña pequeña y su hermano mayor, descrito como el héroe a quien admira, pero que es un soldado sin ejército, un héroe que todavía no tiene catástrofe

\footnotetext{
${ }^{6}$ Monique Wittig señala que "lo que debe romperse es el contrato de heterosexualidad que forma parte implícitamente también sin duda alguna del contrato ideal de Rousseau. Si examino lo que un contrato bien establecido puede realizar por nosotras debo en primer lugar examinar las condiciones históricas y los conflictos que pueden permitirnos poner fin a las obligaciones que nos amordazan sin nuestro consentimiento, ya que no gozamos de reciprocidad, la condición necesaria para nuestra libertad" (Wittig, 2006, p. 61).

$N^{\circ}$ 2. Segundo Semestre de 2014
} 
en la que intervenir; en la ficción del progenitor ausente que invisibiliza las gestiones económicas maternas y en la ficción de la rutina y los paseos con el padre.

Lo masculino acontece como fuerza opresora y liberadora. De esta forma, la niña porta relaciones y significados culturales hegemónicos y masculinos, evidenciados, por ejemplo, en los desafíos que le plantea el hermano y que ella cumple: subir acantilados, trepar árboles, contrapuestos a la ley de la madre que pareciera reclamarle por hacer cosas que no debería. Mientras el hermano le dice: "Hazte hombre", la madre parece decir: "No hagas cosas de hombres". Es el extraño y doble estatuto del lugar de la mujer que se vuelve ley por mandato materno.

Mientras, se viaja sin saber del duelo en otros lugares, con la guerra a cuestas, donde "[e]l fin un fuego de artificio / en el fondo / tu hermano tiene mañas estéticas / lluvia de meteoritos, frentes de guerra para el héroe / amurallado en su propia causa [en quien la niña ve] fuerzas para la revuelta / en vos la revolución" (Nachon, 2013, 17). De esta manera, se "repite la simbólica de los actos sociales de constitución y conformación de la relación entre géneros y que la dejan [a la niña] en una identidad construida, un resultado performativo cuya identidad de género es la repetición estilizada de actos en el tiempo" (Butler, 1998, 297). Reproduce con total plenitud y sin resistencia los roles tradicionales de género, perpetuando el carácter binario de las relaciones filiales en que la felicidad es la mirada del hermano: "Esa es, será tu dicha: un hombre te mira / veinte años y pide luz / para hacer camino. Antes de Roca inundado / el ripio atrapa / al Chevy anaranjado. Vos y él / 
cerrada de lluvia la noche / pala en mano no alcanzás / el metro sesenta pero igual / vas vos con él" (Nachon, 2013, 13).

Vos y él, ella bajo su mirada. Lamentablemente, dice Butler, esta negación o instalación de una supremacía hace fracasar lo que se intenta unir, porque " $[\mathrm{t}] \mathrm{al}$ estrategia, no sólo atribuye una falsa unidad a la heterosexualidad, sino que además deja pasar la oportunidad política de destacar la debilidad de la sujeción heterosexual y de refutar la lógica de exclusión mutua que sustenta el heterosexismo" (2002, p. 170), porque se da en esta relación ese juego ambiguo entre el deseo y el enojo de la niña hacia el hermano, que a veces toma el lugar del padre, por cuanto "el logos tiene un padre [y este] "habla, dice, dicta, y su palabra basta" (Derrida, 1975, p. 112) en tanto él es "un jefe, un capital y un bien" (1975, pp. 119-120). Nachon escribe: "[B]elleza del hermano mayor y su uniforme, la certeza ineludible de su amor" (2013, p. 15).

Se reedita, de esta manera, en la figura del hermano y de la niña la relación de fuerzas. Foucault, parafraseando al Nietzsche de La genealogía de la moral, señala:

"La historia 'efectiva' hace resurgir el suceso en lo que puede tener de úni-co y de agudo [o cortante, preferimos decir]. Acontecimiento -entendido por tal no una decisión, un tratado, un reino, o una batalla-, sino una relación de fuerzas que se invierte, un poder que se confisca, un vocabulario recuperado y vuelto contra los que lo utilizan, una dominación que se debilita, se distiende, ella misma se envenena, y otra que surge, disfrazada [enmascarada]. Las fuerzas que están en juego en la historia no obedecen ni a un destino ni a una 
mecánica, sino el azar de la lucha." (Foucault, 1997, pp. 48-49)

Claro es el pasaje donde la autora escribe: "Que en mis peores pesadillas seas vos / manchado de sangre a mis pies / solamente vos frente a quien / yo me rindo. Que en esas / las peores noches todavía / seas vos a quien busco / infinitamente ahí / rendido a mis pies" (1997, p. 20).

Frente a otra potencia nos rendimos, el espacio se clausura frente a otro opresor. ¿Qué es eso sino un héroe?, cuyas habilidades y hazañas extraordinarias se nos vuelven dignas de imitación. En este par héroe-niña se reproduce y prolonga la distribución y adjudicación instaurados por los hombres en que la mujer cumple y repite su destino, apartada de la historia y al margen de la escena, siendo tachada $y$ reapropiada por el otro. Sin embargo, este juego ambiguo es reflexionado, posteriormente, cuando reaparece la voz de la mujer, la voz de la niña ya adulta, es decir, el recuerdo: "Cuando a Ushuaia vuelvas / serás una mujer en sus cuarenta, paradita ahí / frente a la calma, ahora hermana / de esa niña que fuiste y entendió cómo / aceptar qué cuestiones terminan, cuáles / no tienen fin" (Nachon, 2013, 43).

Este parece ser un gesto de conciliación y hermandad con esa niña que fue y sobrevivió a su guerra particular, pero que resistió para llegar hasta hoy, cuando ya se ha apartado la conciencia y se puede soportar el dolor, en "esa distancia necesaria que establece la mente cuando decide convertirse en observadora y convierte en objeto de observación al yo-cuerpo que padece, es decir, ejercitar en apartarse la conciencia del 
lugar en que se sufre" (Maillard, 2009, p. 131). Es un cambiar de lugar que Maillard denomina sabiduría topológica, es la relación mnemotécnica que tenemos con la escritura. Esta memoria de los hechos, como huella cruel en el cuerpo, diría Nietzsche, marca un nuevo horizonte delimitativo temporal: un presente-porvenir donde el sujeto, para no aniquilarse, evoca y escribe. 


\section{Tercer horizonte: las vías de la memoria}

Patricio Guzmán en su documental Nostalgia de la luz comenta: "[L]os que tienen memoria son capaces de vivir en el frágil tiempo presente, los que no la tienen no viven en ninguna parte". Este ser capaz de vivir significa que no hay otra manera posible de vivir que no sea la errancia del tiempo en el tiempo y de vivir muchas vidas en una vida. Extensión de tiempo anterior que revive el cuerpo limitado y suprimido. ¿Dónde acaece entonces el recuerdo?, ¿dónde el olvido?, ¿dónde la memoria podrá introducir esa ausencia como olvido? ¿Cómo se escribe, para que la nueva venida de aquel recuerdo y para que ese juego jugado en la escritura como conjura del olvido no dañe?

Si seguimos la idea nietzscheana de la memoria como huella cruel en el cuerpo, podemos entender que siempre estamos precipitados en la crueldad. La escena de la crueldad sería la escena del olvido como ausencia o del olvido/ausencia que viene a consagrar que la memoria es violencia cuando olvida y cuando recuerda. Entonces vida de las palabras no como olvido sino en su conmemorar, en la experiencia de memoria que es el poema (Lacoue Labarthe, 2006, p. 31). No hay olvido, solo un descanso, una pausa de las imágenes que vuelven a destellar y se escribe, porque "regreso de la palabra (...) cuando tiembla y se coagula sobre el borde exterior del sentido [como] "una gloria de memoria desprovista de nostalgia, brillante como una moneda nueva encontrada en una tumba, otra especie de hueso y un ruido roto de armas entrechocadas, un golpe de lengua" (Nancy, 2013, p. 12). 
Digamos provisoriamente que se trata de variadas memorias: la memoria íntima o intrínseca de cada uno de los sujetos que viajan; la memoria de esos sujetos entremezclados, por lo tanto memoria exterior o social que es, justamente, la de la catástrofe en medio de la cual se busca un refugio para escapar de la dictadura; y la memoria como medio, resto o escritura de esa memoria dimensionada por la niña que ahora escribe y que intenta explicarse, mucho tiempo después, lo que le ocurrió. Memoria plural y de cruce por el doble vínculo entre la locura familiar, su rostro siniestro, y la locura del país, que ocurren, sin embargo, de manera cotidiana y simultánea. Es en ese movimiento, en ese entre de esas dos memorias, donde el poema emerge como gravitación, de un yo a un tú, pero también de un tiempo a otro, como "la zona de nadie entre eso / que está y aquello / que será tal vez" (2013, p. 57). Relación del sujeto consigo mismo y con lo demás. Necesidad de sí y del que viene, de aquello que soporta ambos pesos en la necesidad de evitar y de remarcar la ausencia. Solo un tiempo de detención para retomar aliento, contarnos y contar con nosotros.

La huella no se borra, la huella insiste. La memoria introduce el olvido y, de igual manera, infiltra el recuerdo. ¿Qué hace la escritura?, ¿nos vuelve sobre la memoria o nos hace olvidar una y otra vez? Ese ahora que porta el pasado, o ese después que de igual manera lo transporta, es quizá el mismo y otro distinto, o no es uno y el mismo. Quizá la sustracción del sujeto, por ejemplo, en el juego, vuelve a subjetivarse a través del recuerdo que no es sino el reverso y el anverso del olvido, siendo la memoria el temblor entre ambos, o "el futuro [que] es solo más pasado que espera acontecer" (D'Aguiar, 
2000, p. 11). Somos lectores y autores en la condición intersticial del poema, en el suspenso de lo que dirá sin decir, porque ante la ausencia de huida solo queda hacer estallar el espacio en el porvenir en un instante entre eso que estamos siendo y lo que seremos, "el tiempo sin fin que lleva a la tierra alcanzar un final" (Nachon, 2013, p. 11).

Lo que queda de esa memoria de la infancia de la niña en el tiempo posterior de la escritura -una memoria intrínseca y una memoria externa, entrelazadas por una memoria que guarda, aún, su carácter difuso- conlleva una oscilación entre dos momentos que la destina a un desconocimiento de sí misma expropiando su identidad. Sin embargo, el sujeto se recupera poéticamente al conmemorar, es decir, al poetizar. El espacio y el tiempo son "kilómetros avanzados [que] acontecen y caen / líneas azules rojas del mapa extendido / igual a la mano abierta de esa niña / que fuiste vos ante sus ojos" (Nachon, 2013, p. 26). Ese que fuiste, retorna como tiempo después del horror, a distancia pero aún tocado por él. Así poetizamos y recobramos sensorialmente, porque, como señala Genovese citando a Bergson, la memoria "no es una facultad de clasificar los recuerdos en un cajón o de inscribirlos en un registro" (2010, p. 70), "no es el amontonamiento del pasado" [sino que como duración] "es el progreso continuo del pasado que corroe el porvenir y que se hincha al avanzar" (Bergson, ctdo. en Genovese, 2010, p. 70). Entiendo, entonces, que la posibilidad de la libertad, como dice Bergson en La risa, tiene que ver con que "no pudiendo presentarse (debido a la duración) un mismo momento dos veces, jamás podrá hablarse, por los hechos de conciencia, de condiciones 
idénticas" (1985, s/p.). En esa duración, en esa memoria, corre algo que es intermitente en sí mismo, nuevo cada vez y único. Este movimiento es el pensamiento poético ${ }^{7}$ : el poema imagina un tiempo anterior donde no había final, porque de las vacaciones se regresa, es solo un breve insilio, un aliento para soportar el peso del mundo, y allí hubo posibilidad de vivir, allí "[h]ubo horizontes abiertos / incontables las estrellas / signaron este viaje, su imperio / para tu familia incapaz / de arribar a un final" (Nachon, 2013, p. 19).

Esta memoria en tres vías, íntima, exterior e intermedia, es como el "agua sin límite: se corta / la respiración y el aire / no alcanza" (Nachon, 2013, p. 30). El sujeto, cuyo comportamiento oscila entre el mundo íntimo (Innenwelt) y el mundo exterior (Umwelt), intenta relacionarse y a través del lenguaje comprende esta escisión y puede vivir entre ambos mundos (Zwischenwelt), pero es precisamente esa dislocación, ese dato perturbador de la realidad, lo que lo lleva a intentar comprender. Ese encontrarse en situación de extrañeza, por la catástrofe y la violencia en su medioambiente y luego frente al otro, lo hace confiarse al lenguaje, lo único con lo cual puede explicarse esta cercanía y distancia respecto de sí mismo, respecto de los otros y respecto del mundo. La poeta se dice a sí misma: "Si cerrás los ojos / todo aquello que viene después será restos, / extrañeza y restos" (Nachon, 2013, p. 55).

La extrañeza en medio de la catástrofe, en términos empíricos e imaginativos es una vivencia en que resuena un

\footnotetext{
7 Alicia Salomone destaca la condición autorreflexiva del género poético, en tanto "la imagen poética siempre queda abierta, posibilitando desplazar la mirada hacia otras direcciones y estimular transformaciones a nivel de la subjetividad" (2011, p. 123).
}

$N^{\circ}$ 2. Segundo Semestre de 2014 
afuera amenazante y un mundo personal e íntimo, cuya única posibilidad para vivir es crear otro mundo y suplantar "una realidad en la que todo se ha vuelto incierto y en que los comportamientos rutinarios son simplemente lo que ha quedado después de una catástrofe. Residuos inexplicables, como ocurre con todo residuo" (Rojas, 2012, p. 46). Se trata de una dislocación ontológica, en el sentido que opera una distancia y extrañeza de un sujeto que intenta vivir en medio de una violencia absoluta. En este mundo personal y social devastado, la subjetividad descentrada encuentra su modo de habitar y resguardarse, allí donde "el horizonte resulta imposible" (Nachon, 2013, p. 33), porque los ciudadanos han comenzado a ser en la persecución "liebres encandiladas" (Nachon, 2013, p. 33). La luz aparece como ante la víctima durante el interrogatorio, durante la huida en el miedo. "El mar [los] acantilados / nada dicen del polvo, las horas gastadas / sobre el conteo de aves rapaces y picos curvos, poco más" (Nachon, 2013, p. 33), porque lo que se cuenta y se registra es solo "Un punto de llegada tras otro: Paso de los Sapos, antes Pirámides/ mucho antes San Antonio" (Nachon, 2013, p. 33). "Cuando todo explote aquí / habrá solaz, jornadas vacías de la Patagonia / harán nuestro refugio / porque el norte se calcinará" (Nachon, 2013, p. 33). Como vemos, el refugio es un lugar distante en el mundo ya clausurado.

Estatuto de la realidad como Innenwelt y Umwelt, en que el poema se aloja en una cavidad en que el sujeto se configura él mismo como algo intermedio. Cruzado y cruzando entre otros y todos no es sino copresencia, interpela desde sí la realidad sin darle la espalda al mundo, entre "grandes ondas de silencio 
vibran[do] en los poemas" (Bachelard, 2000, p. 159). Somos vidas que fluctúan, vidas que tantean, vidas en vibración, el eco que irrumpe en el sujeto en la espera de una noticia terrible, esto es, temblar antes del estallido: "Sobre el ripio / camino a la nada / llueve y llueve cuando nuestro cielo / finalmente estalla" (Nachon, 2013, p. 25). Sobre el ripio, sobre los escombros camino hacia, cuando algo finalmente ocurre, pura alteración, que sin embargo permite este paso hacia lo otro y hacia el lenguaje del otro. Nachon lo explica así:

"Me interesa en particular que el poema como mecanismo vaya a la búsqueda de dos destellos. El primero son ciertas vivencias en que se resuena con un afuera que nos supera, cierto irse de sí que por momentos experimentamos y que es algo sumamente cotidiano, no sé, las formas en que de pronto la luz cruza la calle y vas en ella, o la manera en que escuchás en un bondi la frase 'esa es la causa', o el gesto con que alguien abre las sábanas de la cama. El segundo es un extrañamiento directamente ligado a esas mismas experiencias cotidianas, a una imposibilidad de decodificación (...) en los poemas, momentos de absoluta cercanía o intimidad que a la vez difícilmente conformen ante la mirada un mapa completo: imponen su distancia o su extrañeza, como pedacitos que a veces se unen y hacen sentido y a veces simplemente quedan ahí, suspendidos. Y el poema para mí permite esa simultaneidad y ese extrañamiento donde, si bien hay una zona de representación capaz de generar sentidos, ese sentido no sucede racionalmente o unívocamente; y muchas veces el motor de la escritura que en un principio era alguna imagen o alguna frase cortada, de pronto en el territorio de ese poema o en 
la serie con otros da cuenta de un decir o de una urgencia que evidencia sus sentidos." (Nachon, 2011) ${ }^{8}$

En la serie con otros algo se corta o algo continúa, posibilidad de decir, posibilidad de silenciar, esa es la causa, destellos; irse de sí, pareciera ser el relato de la memoria en esta III Guerra Mundial. La irrecusable dehiscencia en medio del mundo, de nuestro mundo que intentamos narrar para contarnos algo y repararnos. Queda claro en pasajes como el siguiente:

"Como todo

horror cuando se instala parece

jamás comenzó y nunca

podrá terminar. Se retrasa

nuestra vuelta a la vida igual que alguien

pospone cierta operación o el festejo

de un cumpleaños más: nada

dice peligro y el peligro

está. Alucinada

la familia se entrega toda

en velocidad al viaje, cuerpo

hermanado a este desierto y capaz

de esfumarse hecho polvo aunque perdure

mineral e indestructible su estructura." (Nachon, 2013, p. 18)

${ }^{8}$ Las cursivas son mías. 
Herida siempre presente en este y otros libros de Andi Nachon, La III Guerra Mundial cuenta con ese algo que se pospone, con ese mientras, con ese retraso, con la página que es herida y está herida, porque la vida desaparece de golpe y perdura esa extrañeza de cuando algo nos es arrancado de pronto, como si fuese algo que "jamás comenzó y nunca / podrá terminar" (Nachon, 2013, p. 18), cuando, justamente, el horror se vuelve cotidiano y volver a la normalidad no es sino volver a la espectralidad. El tiempo es un promedio de los hechos, la vida es ese estar conviviendo siempre con la posibilidad del horror $y$, entretanto, seguimos viviendo suspendidos y retrasados, en la espera de algo que no sabemos cuándo acabará o cuándo llegará. Estatutos inerciales y pulsantes de la espera que vuelven al sujeto a su animalidad, al acecho del grito, lo feroz de la espera del grito o del grito en su pura mueca, mientras "todavía desespera cada tardanza y se esfuman nombres y amigos" (Nachon, 2013, p. 31).

Un pasaje desolador es este, que además se imbrica con esa inocencia del juego y del viaje traída por la memoria que aún sostiene esa marca inaugural:

"Un regalo te guía en el sueño, cumpleaños de alguien el obsequio tal vez para tu padre aunque no sabés decirlo. Otra vez andás dormida, y antes de abrir los ojos está la asfixia. Un peso feroz sobre vos tirada en el piso, tu pijama es azul 
tiene autitos

tan ciertos como esa presión que hacen

unas manos

en tu cuello. No es su cara

la que va a quedar grabada cuando abras

los ojos al grito. De colados en la fiesta

hermano del medio y madre enmarcan en quietud

la escena. No, no sabés cuándo

despertás o en qué momento el hermano

mayor te suelta $(. .$.

No hay regalo ni sueño y nadie

cumple años en esta casa

rodante donde te levantan y preparan

para seguir viaje

como si nada: 'Camina dormida', verifica

la madre mientras te pasa la ropa

y a otra cosa mariposa." (Nachon, 2013, pp. 35-36)

En medio del horror hay un instante en que tiene lugar una especie de alienación en el juego y el viaje, sin embargo, esa memoria como memoria revelada en el presente trae de regreso el pasado, sus marcas inaugurales como crueldad que retorna. Escribe Nachon: "Tus hermanos juegan simulacros de batalla, estrategias de huida y camuflajes. Al tiempo reclamarás precisiones, indicios capaces de certificar tus fantasías / como eso: una mera fantasía más” (2013, p. 31). 


\section{A modo de conclusión}

Me parece la de Nachon un lucidez, hiriente en que emerge un escritura capaz de componer su distancia y su extrañeza, donde lo escrito es lo posible, lo frágil, pero con un espesor poético y un discernimiento que vulnera, porque el poema exhibe su estatuto pensante y reflexivo. Va hacia un afuera que lo rebasa y retrocede para retomar una senda y comprenderla como posibilidad de futuro. Ese irse fuera de sí, hacia el lenguaje, hacia el otro y hacia el mundo, instala la copresencia irrecusable de la poesía, misterio del encuentro porque está abierta a otros, repartida y, por ello, es una puesta en común de la memoria.

La escritura de La III Guerra Mundial es cercanía íntima y, a la vez, la mirada de una profunda distancia y extrañeza que se defiende de la obscenidad y la voracidad de eso que llamamos realidad. Su micropolítica poética es, justamente, lo que nos hace desear defender esa alteridad, es decir, el lenguaje, que nos recorre y nos cruza diariamente cuando empezamos a leer, a interpelar el mundo y a crear otro, inaugurando aquello que la propia poeta instala como doppelgänger. Somos, cada uno, un sujeto que se bace con y que es respecto de. Ser, en tanto lenguaje y escritura, otro y yo mismo. Nachon señala en el "Ars poética" que escribe para la antología Monstruos:

"Háblame, qué eres tú ahora", preguntaba Muriel Rukeyser desde el poema. Nada que responder, todo por leer, la voluntad de algo por escribir. El poema acontece así en la búsqueda, en la espera. Un laboratorio donde se alzan los instrumentos y se desconoce el nombre de los materiales. Mecanismos, maquinarias y a los que resulta imposible negarse: el placer, el gusto, una antigua estirpe, cómo saberlo. 
Entonces, a veces, conocer o testimoniar o tal vez aprehender: la contundencia de esto que se yergue cuando sucede el poema. El destello de la gratuidad y un espacio para que todo sea posible." (Carrera, 201, p. 104)

En estas formas de hablar de Nachon nos aparece la materia de los días. ¿A quién se destinan los poemas?, ¿quién es el que recibe, quién es el que da?, ¿qué mundo (nos) ponemos por escrito?, ¿cuál es la potencia de los detalles y las cosas pequeñas que rondan el texto? La textualidad de La III Guerra Mundial vuelve a nosotros como espectralidad que nos mira, nos habla y quiere explicarnos el mundo, porque como errancia el poema se despliega y "aquello a lo que abre es la posibilidad de lo imposible" (Oyarzún, 1993, p. 167).

El intento de esta lectura, con Andi Nachon: ir hacia las preguntas que la memoria hace retornar. Ya no nos queda otra cosa sino nombrar en medio de aquello que se resiste, recoger señales, decir recordando la voz de Andi "entre un yo y un vos [e] instalar la potencialidad de un chispazo" (Nachon, 2011). El poema, su apertura del propio ser al otro, es demasiado pronto o demasiado tarde: acontecimiento y herida de la lengua donde, quizás, "mucho después buscarás rastros / a tu forma una memoria / su posible redención” (Nachon, 2013, p. 19). Memoria entonces como intento, segunda vez difuso e incierto para explicarnos aquello que nos sucedió, como ocurre al final de la película Sur de Fernando "Pino" Solanas registrado en la voz del bandoneonista que canta "mi barrio era así, así, así... es decir, qué sé yo si era así".

Se acude a la escritura para recordar e inscribir aquello que se recuerda, y si el acto de escribir es un acto de memoria 
o aquello que ocurre por segunda vez, esta segunda vez de la escritura no ocurre como mera repetición, sino como reparación, porque la simple "repetición implica un pasaje al acto. No se vive la distancia con el pasado, que reaparece y se mete, como un intruso, en el presente [es] un doble peligro: el de un 'exceso de pasado' en la repetición ritualizada, en la compulsión que lleva al acto, y el de un olvido selectivo, instrumentalizado y manipulado" (Jelin, 2000, p. 14). Ella es la manera en que "cada uno tiene su propio después para intentar comprender y soportar lo insoportable" (Derrida, 1971, p. 31). Soportar en el intersticio, desde él ir y volver, disipar la homogeneidad, porque en ese tiempo, que aún no conocemos, sigue abierto aquello que olvidamos y la posibilidad del pensamiento y del poema. 


\section{Bibliografía}

Agamben, G. (2001). "El país de los juguetes. Reflexiones sobre la historia y el juego". Infancia e historia (traducción de Silvio Mattoni). Buenos Aires, Argentina: Adriana Hidalgo Editora.

Bachelard, G. (2000). La poética del espacio. México D. F.: Fondo de Cultura Económica.

Bergson. H. (1985). La risa. Madrid, España: Sarpe.

Butler, J. (2002). Cuerpos que importan. Sobre los límites materiales y discursivos del "sexo". Buenos Aires, Argentina: Paidós. (1998). "Actos performativos y constitución del género: un ensayo sobre fenomenología y teoría feminista". Debate Feminista, 18.

Cacciari, M. (2000). El dios que baila. Buenos Aires, Argentina: Paidós.

Carrera, A. (2001). Monstruos. Antología de la joven poesía argentina. Buenos Aires, Argentina: Fondo de Cultura Económica.

D’Aguiar, F. (2000). La memoria más larga. Santiago, Chile: Editorial Andrés Bello.

Derrida, J. (1975). La diseminación. Madrid, España: Fundamentos.

(1971). De la gramatología. Buenos Aires, Argentina: Siglo XXI Editores.

Foucault, M. (1997). Nietzssche, la genealogía, la historia. Madrid, España: Pre-Textos.

Genovese, A. (2011). Leer poesía. Lo leve, lo grave, lo opaco. Buenos Aires, Argentina: Fondo de Cultura Económica. (2010). "Entre la ira y el arte del olvido: testimonio e imagen poética". Recordar para pensar. Memoria para la 
Democracia. La elaboración del pasado reciente en el Cono Sur de América Latina. Santiago, Chile: Ediciones Böll Cono Sur. (2003). "Marcas del graffiti en los suburbios: poesía argentina de la postdictadura". Revista Iberoamericana, Pittsburgh, Estados Unidos.

(1998). La doble vo\%. Poetas argentinas contemporáneas. Buenos Aires, Argentina: Biblos.

Heidegger, M. (2002). De camino al habla. Barcelona, España: Ediciones del Serbal.

Jelin, E. (2002). Los trabajos de la memoria. Madrid, España: Siglo XXI Editores.

Lacoue-Labarthe, P. (2007). La poesía como experiencia. Trad. José Francisco Megías. Madrid, España: Arena Libros.

Levinas, E. (1995). "Paul Celan. Del ser al otro". Nombres, Revista de Filosofía, Córdoba, año $\mathrm{V}, \mathrm{N}^{\circ} 6$ [en línea], http://www.revistas.unc.edu.ar/index.php/NOMBRES/ article/view/2083.

Maillard, C. (2009). Contra el arte y otras imposturas. Valencia, España: Pre-Textos.

Malabou, C. (2010). La plasticidad en espera. Santiago, Chile: Palinodia.

Marchant, P. (2009). Sobre árboles y madres. Buenos Aires, Argentina: Ediciones La Cebra.

Nachon, A. (2013). La III Guerra Mundial. Buenos Aires, Argentina: Bajo la Luna. (2011). Entrevista a Andi Nachon, "Micropolíticas de la resistencia", por Aníbal Cristobo [en línea], http://kriller71.blogspot.com/2011/08/entrevista-andinachon-micropoliticas.html, domingo, 14 de agosto. 
Nancy, J-L. (2013). Lengua apócrifa. Trad. Juan Soros. Santiago, Chile: Cuadro de Tiza Ediciones.

Oyarzún, P. (1993). "Lengua, lugar, abismo". Utopia(s). Seminario Internacional. Santiago de Chile, División de Cultura Ministerio de Educación (Mesa: La ley de los idiomas y la dispersión de la lengua).

Rojas, S. (2012). Catástrofe y trascendencia en la narrativa de Diamela Eltit. Santiago, Chile: Sangría Editora.

Salomone, A. (2011). "Ecos antiguos en voces nuevas. Posmemorias poéticas de mujeres en Chile y Argentina", América sin Nombre, $\mathrm{N}^{\mathrm{o}} 16$ [en línea], http://rua.ua.es/dspace/handle/10045/20645. (2011). "Poesía, memoria y comunidad nacional. Chile y Argentina en postdictadura". Revista Sociedad \& Equidad, $\mathrm{N}^{\circ} \quad 1, \quad$ enero [en línea], http://www.sye.uchile.cl/index.php/RSE/article/viewAr ticle/10605/10843.

Wittig, M. (2006). El pensamiento heterosexual y otros ensayos. Madrid, España: Editorial Egales. 